\title{
Temperature- and pH-Controlled Hydrogelation of Poly(ethylene glycol)-Grafted Hyaluronic Acid by Inclusion Complexation with $\alpha$-Cyclodextrin
}

\author{
Tsuyoshi NAKAMA, Tooru OOYA, and Nobuhiko YUI ${ }^{\dagger}$ \\ School of Materials Science, Japan Advanced Institute of Science and Technology, \\ 1-1 Asahidai, Tatsunokuchi, Ishikawa 923-1292, Japan
}

(Received December 9, 2003; Accepted February 3, 2004)

\begin{abstract}
A series of poly(ethylene glycol) (PEG)-grafted hyaluronic acid (HA) was prepared by condensation reaction with hydrazide-terminated PEG using water soluble carbodiimide. PEG-grafted HA $(\mathrm{P} g \mathrm{H})$ solutions exhibited hydrogelation on adding $\alpha$-cyclodextrin $\left(\alpha\right.$-CD). The solid-state ${ }^{13} \mathrm{C} \mathrm{CP} / \mathrm{MAS}$ NMR spectroscopic and powder X-Ray diffraction measurements revealed the formation of inclusion complex between the PEG grafts and $\alpha$-CD. The gel-melting temperature increased with increasing the degree of substitution of the PEG grafts and decreasing pH of aqueous medium. These results indicate that $\mathrm{P} g \mathrm{H}$ hydrogels were constructed by inclusion complexation between the PEG grafts and $\alpha-\mathrm{CD}$, and the gel-melting temperature could be controlled by both the degree of substitution of the PEG grafts and $\mathrm{pH}$.

KEY WORDS Hyaluronic Acid / Inclusion Complex / $\alpha$-Cyclodextrin / Poly(ethylene glycol) / Hydrogelation /
\end{abstract}

Recently, much attention has been paid to supramolecular-structured hydrogels due to their advantages for biomedical applications. Since these hydrogels can be formed by non-covalent interactions such as hydrogen bonding, ionic interaction, hydrophobic interaction, stereo complexation, and inclusion complexation, there is no need to use organic solvents or harmful reagents as a crosslinker. Supramolecularstructured hydrogels have been expected to show stimuli-reversibility due to their non-covalent bonding. These properties are useful for biomedical applications such as injectable drug delivery systems. Akiyoshi et al. reported cholesterol-bearing pullulan forms nanoparticle hydrogels by hydrophobic interaction. ${ }^{1}$ This cholesterol-bearing pullulan hydrogels can entrap model proteins into hydrophobic domains formed by cholesterols. Hennink et al. reported that L-lacic acid- and R-lactic acid-grafted dextrans could form stereocomplex hydrogels by mixing equal amounts of the dextran derivatives. ${ }^{2}$ A model protein entrapped in the stereocomplex hydrogels could be released over $6 \mathrm{~d}$ with degradation of hydrogels. Hoffman et al. reported a new mucoadhesive drug delivery carriers based on hydrogen bonded complexes of poly(acrylic acid) with poly(ethylene glycol) (PEG). ${ }^{3}$ Li et al. reported a supramolecular-structured hydrogel composed of high molecular weight PEG and $\alpha$-cyclodextrin $(\alpha$-CD), which showed a reversible sol-gel phase transition. ${ }^{4}$

Over the past few years, our research group has reported supramolecular-structured hydrogels for bio- medical applications such as drug carriers and tissue scaffolds. ${ }^{5,6}$ Recently, Huh et al. reported hydrogels formed by inclusion complexation between short PEG-grafted dextran and $\alpha$-CD, which showed a unique sol-gel phase transition. ${ }^{7}$ In that system, inclusion complexes (ICs) between the PEG graft and $\alpha$-CD readily associate each other due to the strong intermolecular hydrogen bonds of $\alpha-\mathrm{CD}$, which act as physical crosslinks. Furthermore, thermoreversible hydrogels based on inclusion complexation between poly(propylene glycol)-grafted dextran (PPG-grafted dextran) and $\beta$-CD were also reported. ${ }^{8}$ The phase transition temperature of the hydrogels could be controlled by the number of grafts or the feed ratio of $\beta$-CD to PPG-grafted dextran. These properties would be useful for biomedical applications. However, dextran as a polymeric backbone in those systems could not be degraded in human body. Therefore, it is needed to use another polymeric backbone which can be degraded in human body.

Hyaluronic acid (HA) is a polysaccharide composed of repeating disaccharide units of $\mathrm{N}$-acethylD-glucosamine (GlcNAc) and D-glucuronic acid (GlcUA). HA has been extensively studied as biocompatible and biodegradable polymers for drug delivery and tissue engineering. ${ }^{9} 10$ It is well known that HA hydrogels can be degraded by hyaluronidase or hydroxyl radicals derived from inflammation in human body. ${ }^{11}$ From the biological characters, we hypothesized that the use of HA instead of dextran forms supramolecular-structured hydrogels which can be de-

${ }^{\dagger}$ To whom correspondence should be addressed (Tel: +81-761-51-1640, Fax: +81-761-51-1645, E-mail: yui@jaist.ac.jp). 
graded in human body. Due to high molecular weight of HA, the hydrogels are expected to be formed at relatively low concentrations of PEG-grafted $\mathrm{HA}(\mathrm{P} g \mathrm{H})$. Many carboxyl groups may lead to $\mathrm{pH}$-dependent volume changes induced by ionization of the carboxyl groups.

In this study, a series of $\mathrm{P} g \mathrm{H}$ was prepared to form hydrogels by inclusion complexation with $\alpha-\mathrm{CD}$. The supramolecular-structured hydrogels were characterized by solid-state ${ }^{13} \mathrm{C} \mathrm{CP} /$ MAS NMR and powder XRay diffraction measurements. The gel-melting temperature of these hydrogels based on inclusion complexation between the PEG grafts and $\alpha$-CD was estimated with different $\mathrm{pHs}$.

\section{EXPERIMENTAL}

\section{Materials}

PEG monomethyl ether (MeO-PEG-OH, $M_{\mathrm{n}}=$ 2,000) was purchased from Aldrich Chemical Co., Inc. (Milwaukee, WI USA). Succinic anhydride, $N$, $N^{\prime}$-dicyclohexylcarbodiimide (DCC), and $N$-hydroxysuccinimide (HOSu) were purchased from Nacalai Tesque, Inc. (Kyoto, Japan). Hydrazine hydrate and $\alpha$-CD were purchased from Wako Pure Chemical Industries, Ltd. (Osaka, Japan). Water soluble carbodiimide (1-ethyl-3-(dimethylamino) carbodiimide, hydrochloride; WSC) was purchased from DOJINDO Labs. (Kumamoto, Japan). Sodium hyaluronate (HA) $\left(M_{\mathrm{n}}=90,000\right)$ was supplied from Chisso Co. (Tokyo, Japan). MeO-PEG-OH was used after drying in vacuo at $100^{\circ} \mathrm{C}$ for $24 \mathrm{~h}$. All other chemicals were used as received without further purification.

\section{Preparation of Hydrazide-Terminated PEG}

Hydroxyl groups of MeO-PEG-OH were allowed to react with succinic anhydride in toluene at $150^{\circ} \mathrm{C}$ for $5 \mathrm{~h}$. The mixture was cooled and then poured into excess ether to obtain crude products. The crude prod- ucts were dissolved in methylene chloride and the resulting insoluble products were removed. The solute was added to excess ether to obtain a carboxy-terminated PEG. The carboxy-terminated PEG was activated by HOSu and DCC in a mixture of 1,4-dioxane and methylene chloride $(1: 1 \mathrm{v} / \mathrm{v})$ at room temperature for $12 \mathrm{~h}$. After filtration of dicyclohexyl urea, the filtrate was concentrated by evaporation, followed by pouring into excess ether to obtain a HOSu-activated PEG. The HOSu-activated PEG was allowed to react with hydrazine hydrate in methanol at room temperature for $12 \mathrm{~h}$. The solution thus obtained was concentrated by evaporation, precipitated in excess ether, and dried in vacuo.

${ }^{1} \mathrm{H}$ NMR (ppm): 2.40 ( $\mathrm{m}, \mathrm{CH}_{2}$ of succinate), 3.28 (s, $\mathrm{CH}_{3}$ of $\left.\mathrm{PEG}\right), 3.62$ (s, $\mathrm{CH}_{2}$ of $\left.\mathrm{PEG}\right), 4.12$ (m, $-\mathrm{CH}_{2}-\mathrm{OC}(\mathrm{O})-$ of PEG).

FT-IR $\left(\mathrm{cm}^{-1}\right): 1635$ ( $v \mathrm{CO}$ of amide I), $1540(v \mathrm{NH}$ of amide II).

\section{Preparation of $\mathrm{PgH}$}

A series of $\mathrm{PgH}$ was prepared according to a previously reported method. ${ }^{12} \mathrm{HA}$ and the hydrazide-terminated PEG (MeO-PEG-HZ) were dissolved in pure water. The $\mathrm{pH}$ of the solution was adjusted to 4.75 using $0.1 \mathrm{~N} \mathrm{HCl}$, and WSC was then added as a solid form. The feed conditions were summarized in Table I. The $\mathrm{pH}$ of the reaction solution was maintained at 4.75 during the reaction for $2 \mathrm{~h}$. After that, the $\mathrm{pH}$ of the resulting solution was adjusted to 7.0 by adding $1 \mathrm{~N} \mathrm{NaOH}$. The solution was exhaustively dialyzed (molecular weight cut-off $=15000$ ) against distilled water and then lyophilized. The degree of substitution (DS) of the PEG grafts was calculated by comparing the NMR peak area of the signal at $1.9 \mathrm{ppm}\left(\mathrm{CH}_{3}\right.$, acetyl of $\left.\mathrm{HA}\right)$ with that at $3.6 \mathrm{ppm}$ $\left(\mathrm{CH}_{2}\right.$ of $\left.\mathrm{PEG}\right)$.

${ }^{1} \mathrm{H}$ NMR (ppm): 1.88 (bs, $-\mathrm{C}(\mathrm{O}) \mathrm{CH}_{3}$ of $\left.\mathrm{HA}\right), 3.20$ 4.53 (-CH- of HA), $3.62\left(-\mathrm{CH}_{2}-\right.$ of PEG).<smiles>COCCOCCOCCOCCOC</smiles>

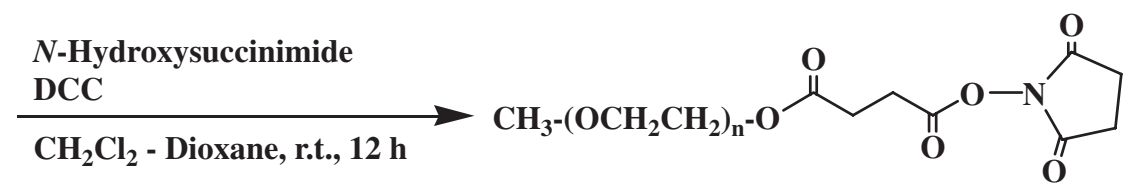<smiles>CCCCCCOCCOC(=O)CCC(=O)NN</smiles>

Figure 1. Synthetic route for hydrazide-terminated PEG. 
Table I. Preparation and characterization of $\mathrm{PgH}$

\begin{tabular}{|c|c|c|c|c|c|c|c|}
\hline \multirow{2}{*}{ Code } & \multicolumn{2}{|c|}{ HA } & \multicolumn{2}{|c|}{ MeO-PEG-HZ } & \multirow{2}{*}{$\mathrm{DS}^{\mathrm{a}}$} & \multirow{2}{*}{$\begin{array}{c}\text { PEG content }{ }^{\mathrm{b}} \\
(\mathrm{wt} \%)\end{array}$} & \multirow{2}{*}{$\begin{array}{l}\text { Total } \\
M_{\mathrm{n}}^{\mathrm{c}}\end{array}$} \\
\hline & $M_{\mathrm{n}}$ & $\mathrm{mmol}$ & $M_{\mathrm{n}}$ & $\mathrm{mmol}$ & & & \\
\hline $\mathrm{P} g \mathrm{H}-1$ & 90,000 & 1 & 2,000 & 0.13 & 0.09 & 31 & 130,500 \\
\hline $\mathrm{P} g \mathrm{H}-2$ & 90,000 & 1 & 2,000 & 0.25 & 0.18 & 47 & 171,000 \\
\hline $\mathrm{PgH}-3$ & 90,000 & 1 & 2,000 & 0.38 & 0.28 & 58 & 216,000 \\
\hline
\end{tabular}

${ }^{a}$ The degree of substitution of the PEG grafts was determined by ${ }^{1} \mathrm{H}$ NMR spectra. ${ }^{\mathrm{b}} \mathrm{PEG}$ content was calculated from the DS of the PEG grafts. ${ }^{\mathrm{c}}$ The number-average molecular weight of $\mathrm{P} g \mathrm{Hs}$ was estimated by the peak integration of ${ }^{1} \mathrm{H}$ NMR spectra.

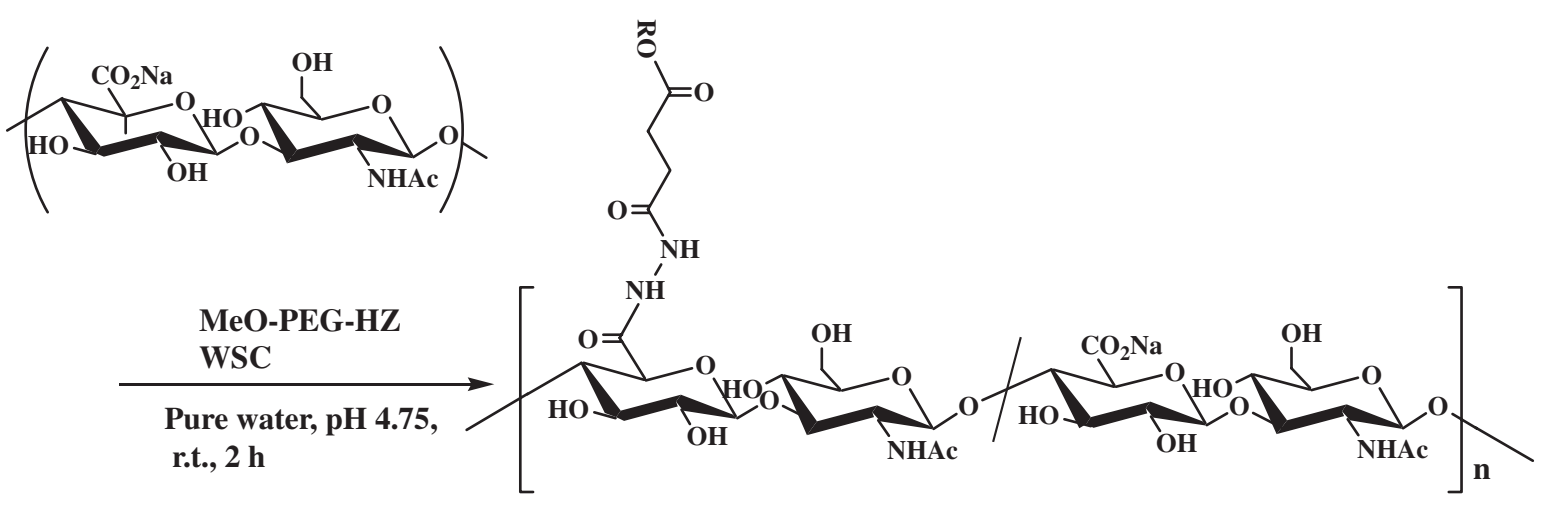

$\mathrm{R}: \mathrm{CH}_{3}-\left(\mathrm{OCH}_{2} \mathrm{CH}_{2}\right)_{\mathrm{m}^{-}}$

Figure 2. Synthetic route for PEG-grafted HA.

\section{Preparation of ICs between $\mathrm{PgH}$ and $\alpha-C D$}

The ICs of $\mathrm{P} g \mathrm{H}$ were prepared by adding an aqueous solution of $\alpha$-CD into glass tubes containing $\mathrm{P} g \mathrm{H}$. The mixture was kept vigorous stirring at room temperature until precipitation was observed. The feed molar ratio of the repeating unit of PEG to $\alpha$-CD ([EG]/[CD]) was 2 . In a similar manner, an IC between PEG and $\alpha$-CD was prepared as a reference of the $\mathrm{P} g \mathrm{H} / \alpha$-CD ICs. The precipitated PEG $/ \alpha-\mathrm{CD}$ IC was separated by centrifugation and washed with distilled water and then dried in vacuo.

\section{Characterization}

The chemical structure of the MeO-PEG-HZ and the $\mathrm{P} g \mathrm{H}$ was analyzed by ${ }^{1} \mathrm{HNMR}(300-\mathrm{MHz}$ FTNMR spectrometer; Varian, Unity plus, CA, USA) and FT-IR spectroscopic measurements (FT/IR-460, Jasco Corp., Japan). Threading of $\alpha$-CD onto the PEG grafts was characterized by the solid-state ${ }^{13} \mathrm{C}$ CP/MAS NMR spectra at $100.4 \mathrm{MHz}$ on a JNMGSX 400 NMR spectrometer with a sample spinning rate of $6 \mathrm{KHz}$ at $19^{\circ} \mathrm{C}$. $\mathrm{CP}$ spectra were acquired with a 5-ms contact time, a 12-s repetition time and 18000 accumulations. Powder X-Ray diffraction measurements were performed with a powder diffractometer (RINT2000, Rigaku, Japan) and two-dimensional image-plate photography using graphite-monochromatized $\mathrm{CuK}_{\alpha}$ radiation $(\lambda=1.542 \AA)$. The $\mathrm{pH}$ - and temperature-dependent dissociation of ICs was examined by a UV-vis spectrophotometer at $500 \mathrm{~nm}$ with a monotonic temperature increase of $2{ }^{\circ} \mathrm{C}$ per min $(\mathrm{V}$ 550, Jasco Corp., Japan). The gel-melting temperature $\left(T_{\text {gel-melt }}\right)$ was determined by a vial inversion method with a monotonic temperature increase of $1{ }^{\circ} \mathrm{C}$ per step. The $T_{\text {gel-melt }}$ was visually monitored with elevating temperature and defined as a critical temperature at which the hydrogel started to flow by inverting the vials.

\section{RESULTS AND DISCUSSION}

A series of $\mathrm{P} g \mathrm{Hs}$ with different DSs of the PEG grafts was prepared by condensation reaction of HA with MeO-PEG-HZ. From the NMR spectra, all the peaks attributed to PEG and HA were confirmed. The result of the synthesis of $\mathrm{PgHs}$ is summarized in Table I. The DS of the PEG grafts was well controlled by changing the feed ratio of PEG to HA. In this experiment, the DS of the PEG grafts ranged from 0.09 to 0.28 . It is well known that PEG can form ICs with $\alpha$-CD with a stoichiometry $[\mathrm{EG}] /[\mathrm{CD}]=$ $2 .{ }^{13}$ It was reported that the crystalline aggregates of ICs form physical crosslinks when PEG-grafted dextran was mixed with $\alpha$-CD. ${ }^{7}$ The crystallinity of ICs was decreased by adding excess amount of $\mathrm{CD}$, resulting in decreasing gel-melting temperature. ${ }^{8}$ Therefore, in this study, $\alpha$-CD was added to $\mathrm{P} g \mathrm{H}$ solution with a stoichiometry of 2 . When $\alpha$-CD was added to $\mathrm{P} g \mathrm{H}$ in 
Hyaluronic Acid-Based Hydrogelation

Table II. Hydrogelation of $\mathrm{P} g \mathrm{H}$ with $\alpha$-CD

\begin{tabular}{ccccccc}
\hline \multirow{2}{*}{ Code } & DS & \multicolumn{5}{c}{ Concentration of $\mathrm{PgH}(\mathrm{wt} \%)$} \\
\cline { 3 - 6 } & & 0.1 & 0.5 & 1.0 & 2.0 & 3.0 \\
\hline \multirow{2}{*}{$\mathrm{P} g \mathrm{H}-1$} & 0.09 & Clear & Turbid & Turbid & Turbid gel & Turbid gel \\
& & $(0.16)^{\mathrm{a}}$ & $(0.78)$ & $(1.6)$ & $(3.1)$ & $(4.7)$ \\
$\mathrm{P} g \mathrm{H}-2$ & 0.18 & Clear & Turbid & Turbid & Turbid gel & Turbid gel \\
& & $(0.24)$ & $(1.2)$ & $(2.4)$ & $(4.7)$ & $(7.1)$ \\
$\mathrm{P} g \mathrm{H}-3$ & 0.28 & Clear & Turbid & Turbid gel & Turbid gel & Turbid gel \\
& \multirow{2}{*}{$0.29)$} & $(1.5)$ & $(2.9)$ & $(5.8)$ & $(8.8)$ \\
\hline
\end{tabular}

${ }^{\mathrm{a}}$ Concentration of the PEG grafts in the $\mathrm{P} g \mathrm{H}$ solution $(\mathrm{mM})$

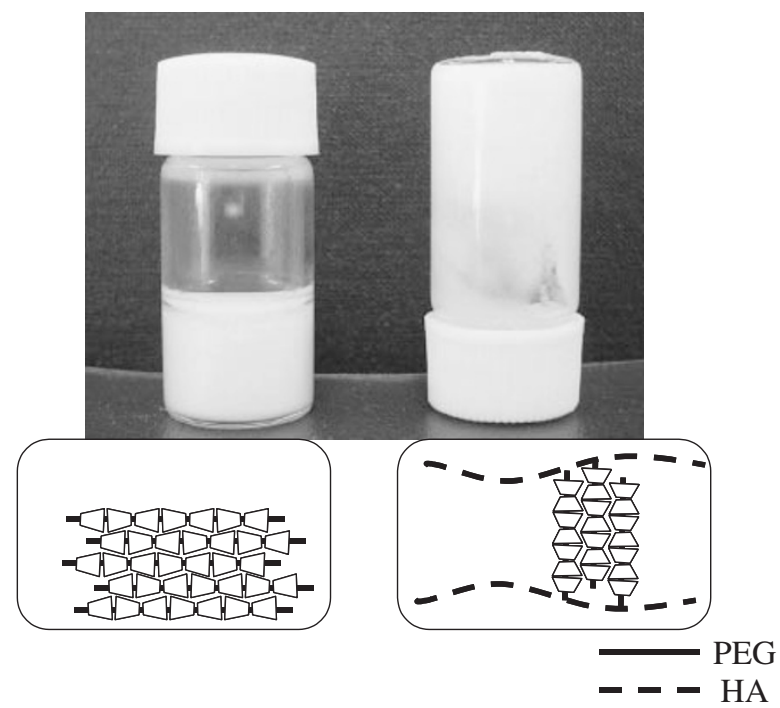

(a)

(b)

Figure 3. Photograph of IC formation on adding $\alpha$-CD to (a) physically mixed MeO-PEG-OH/HA solution, and (b) $\mathrm{P} g \mathrm{H}-3$ solution.

$0.1 \mathrm{M}$ phosphate buffer solution at $\mathrm{pH} 7$, the solution became hydrogel and/or turbid, depending on the concentration of $\mathrm{P} g \mathrm{H}$. Visible change of $\mathrm{P} g \mathrm{H}$ solutions, observed when $\alpha$-CD was added at $\mathrm{pH} 7$, is summarized in Table II. When the concentration of $\mathrm{P} g \mathrm{H}-1$ was $0.5 \mathrm{wt} \%$, the solution became turbid. When the concentration of $\mathrm{P} g \mathrm{H}-1$ reached $2.0 \mathrm{wt} \%$, the solution exhibited hydrogelation. On the other hand, $\mathrm{P} g \mathrm{H}-3$ formed hydrogel above the concentration of $1.0 \mathrm{wt} \%$. As for the concentration of the PEG graft, the turbid solution was obtained when the PEG graft concentration was from 0.8 to $3.0 \mathrm{mM}$, while the solutions containing above $3.0 \mathrm{mM}$ of the PEG graft became hydrogels. When $\alpha$-CD was added to a physically mixed $\mathrm{HA} / \mathrm{MeO}-\mathrm{PEG}-\mathrm{OH}$ solution with the same composition as $\mathrm{P} g \mathrm{H}-3$ (3 $\mathrm{wt} \%$ ), IC was obtained as crystalline precipitates (Figure 3 ). These results suggest that the crystalline aggregates of ICs between the PEG grafts and $\alpha$-CD act as physical crosslinks in the hydrogels.

In our previous study, PEG-grafted dextran formed hydrogels on adding $\alpha$-CD with relatively high con-

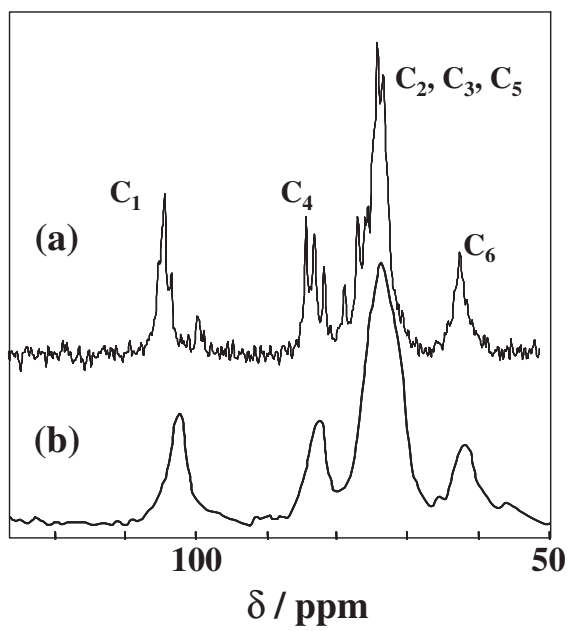

Figure 4. Solid-state ${ }^{13} \mathrm{C} \mathrm{CP} / \mathrm{MAS}$ NMR spectra of (a) $\alpha$-CD and (b) $\mathrm{P} g \mathrm{H}-1 / \alpha-\mathrm{CD}$ IC.

centrations (above $20 \mathrm{wt} \%)^{7}$ On the other hand, the hydrogelation of $\mathrm{P} g \mathrm{H}$ proceeded at relatively low concentrations (above $2.0 \mathrm{wt} \%$ ). These results suggest that HA backbone is superior to dextran backbone, with respect to gelation properties though the inclusion complexation.

To prove ICs between the PEG grafts and $\alpha-\mathrm{CD}$ in the hydrogels, the solid-state ${ }^{13} \mathrm{C} \mathrm{CP} / \mathrm{MAS}$ NMR and powder X-Ray diffraction measurements were carried out. Figure 4 shows the solid-state ${ }^{13} \mathrm{C} \mathrm{CP} / \mathrm{MAS}$ NMR spectra of $\alpha$-CD (a) and the lyophilized $\mathrm{P} g \mathrm{H}-$ $1 / \alpha$-CD IC (b). It is assumed that $\alpha$-CD has a less symmetrical conformation in the crystal when it does not include a guest in the cavity. ${ }^{14}$ Multiple resolved C-1 and C-4 resonances of (each carbon type of) $\alpha$ CD were observed (Figure 4a). On the other hand, these multiple resolved resonances were not observed in $\mathrm{P} g \mathrm{H}-1 / \alpha$-CD IC, and each carbon resonance appeared in a single peak (Figure $4 \mathrm{~b}$ ). These results indicate that $\alpha$-CD assumes a symmetrical conformation due to the inclusion complexation with the PEG grafts. A result of the powder X-Ray diffraction study also supported the inclusion complexation between the PEG grafts and $\alpha$-CD. Figure 5 shows the powder $\mathrm{X}$-Ray diffraction patterns of the lyophilized $\mathrm{P} g \mathrm{H}-1 /$ $\alpha$-CD IC and constituent molecules. It is well known 


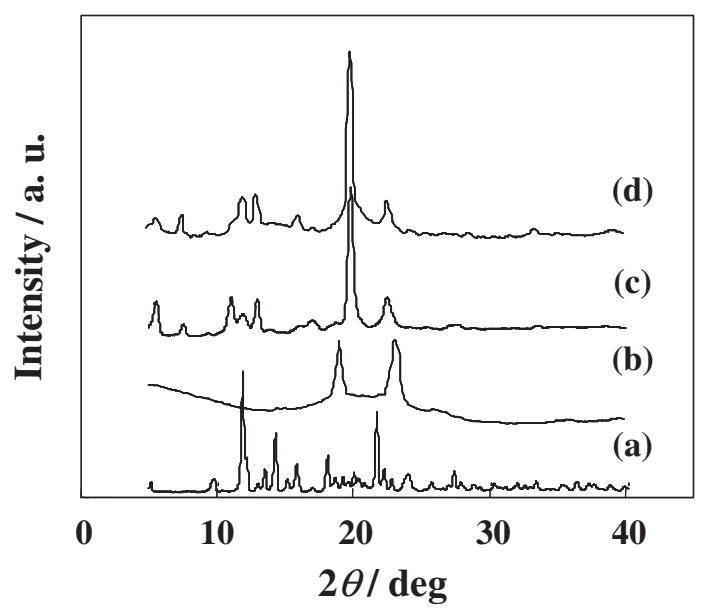

Figure 5. Powder X-Ray diffraction patterns for (a) $\alpha-\mathrm{CD}$, (b) $\mathrm{P} g \mathrm{H}-1$, (c) $\mathrm{PEG} / \alpha-\mathrm{CD}$ IC, and (d) $\mathrm{P} g \mathrm{H}-1 / \alpha-\mathrm{CD}$ IC.

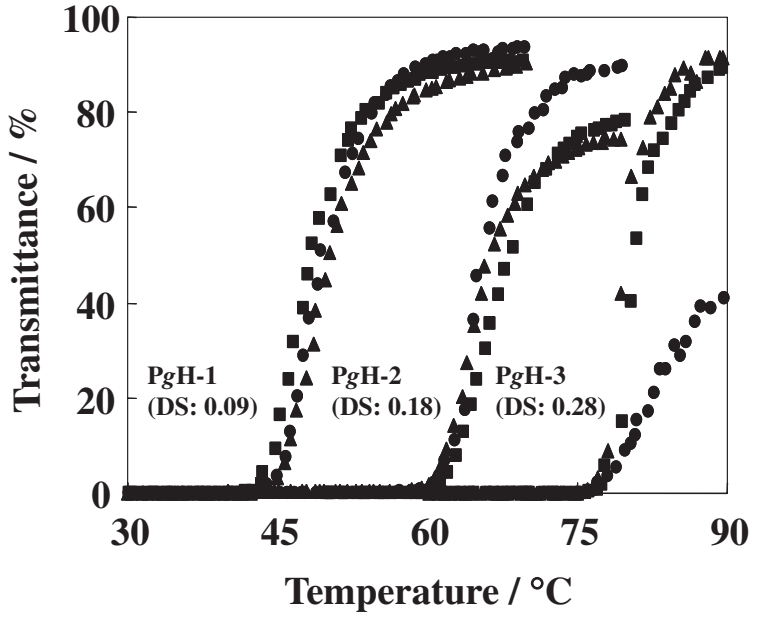

Figure 7. Change in light transmittance of $\mathrm{P} g \mathrm{H} / \alpha$-CD ICs as a function of temperature in $0.1 \mathrm{M}$ buffer solution, measured at different pHs: $\bullet, \mathrm{pH} 4 ; \boldsymbol{\Delta}, \mathrm{pH} 7 ; \boldsymbol{\square}, \mathrm{pH} 9$.

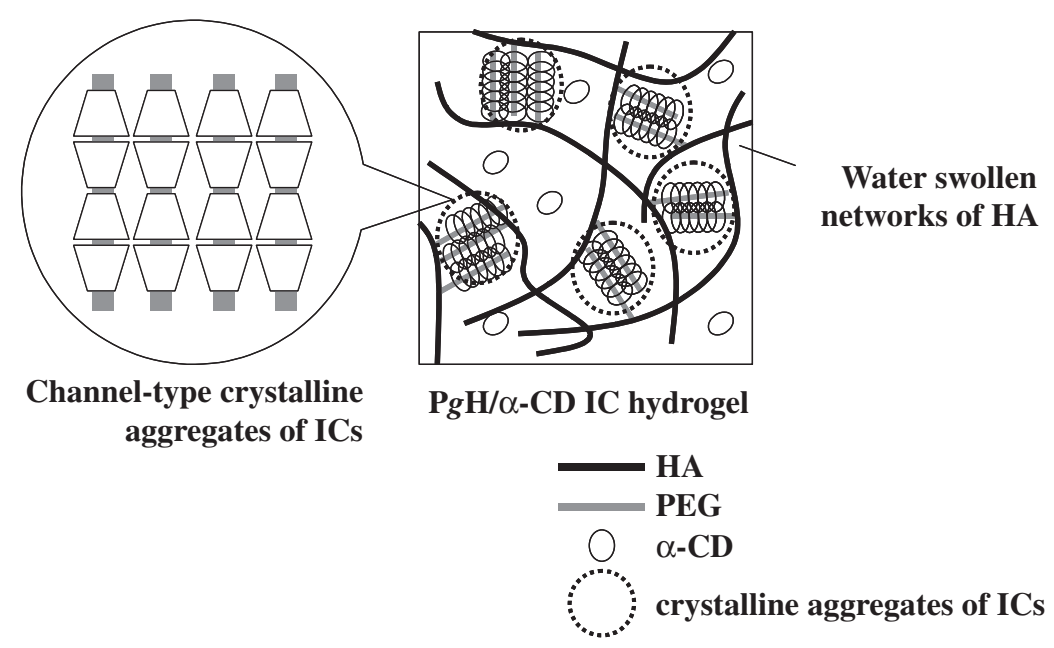

Figure 6. Possible image for $\mathrm{P} g \mathrm{H} / \alpha$-CD IC hydrogel.

that ICs between polymeric guests and CD form a channel-type crystalline structure. ${ }^{13}$ The diffraction pattern of $\mathrm{P} g \mathrm{H}-1 / \alpha-\mathrm{CD}$ IC exhibited a sharp diffraction peak at $2 \theta=20.0^{\circ}(d=4.44 \AA)$ (Figure $\left.5 \mathrm{~d}\right)$. This pattern was quite similar to that of well-characterized $\mathrm{PEG} / \alpha$-CD IC (Figure 5c). Thus, the channel-type crystalline structure of $\mathrm{P} g \mathrm{H} / \mathrm{CD}$ ICs exists in the dried state. Since the ICs between PEG and $\alpha$-CD were insoluble at relatively higher concentrations in the hydrogels, the turbidity of the obtained hydrogels (Table II) should come from the crystalline aggregates of ICs. Thus, it is suggested that the crystalline aggregates of ICs consisting of $\alpha$-CD and the PEG grafts as physical crosslinks are dispersed into water-swollen networks of $\mathrm{HA}$ in $\mathrm{P} g \mathrm{H} / \alpha$-CD IC hydrogel (Figure 6).

The advantages of $\mathrm{HA}$ as a polymeric backbone may include the possession of carboxyl groups responsible for $\mathrm{pH}$-dependent volume changes and the stability of the hydrogel due to the relatively higher viscosity of HA. Figure 7 shows the change in the transmittance of visible light $(\lambda=500 \mathrm{~nm})$ for $\mathrm{P} g \mathrm{H} /$ $\alpha$-CD IC suspensions containing $0.5 \mathrm{wt} \% \mathrm{P} g \mathrm{H}$, examined as a function of temperature under different $\mathrm{pHs}$ conditions. At this $\mathrm{P} g \mathrm{H}$ concentration, the solutions became turbid on adding $\alpha$-CD but did not form hydrogels (see Table II). The turbidimetry measurements made clearer the stability of physical crosslinks formed by ICs. As can be seen in Figure 7, the transmittance of the $\mathrm{P} g \mathrm{H} / \alpha$-CD IC suspensions with mutually different DSs rapidly increased at a certain critical temperature, indicating that the IC between PEG grafts and $\alpha$-CD in the respective suspensions dissociated rapidly. Furthermore, the dissociation temperature increased with DS of $\mathrm{PgH}$. It is presumed that intermolecular hydrogen bonding between adjacent $\alpha$ CDs, possibly as a major driving force for the inclusion complexation with PEG, would be eliminated at the dissociation temperature. As far as a given $\mathrm{P} g \mathrm{H}$ 
was concerned, however, this dissociation temperature was almost independent on $\mathrm{pH}$ examined. It is considered that ionization of carboxyl groups in $\mathrm{P} g \mathrm{H}$ does not affect the dissociation events, presumably due to their relatively low concentrations $(3.8 \mathrm{mM}$ for $\mathrm{PgH}$ 3 ). As to the transmittance change above the dissociation temperature, a different $\mathrm{pH}$-dependency was observed at $\mathrm{P} g \mathrm{H}$ of $\mathrm{DS}=0.28$ : the transmittance increment with temperature at $\mathrm{pH} 4$ was rather smaller than those at $\mathrm{pH} 7$ and 9. Since carboxyl groups of $\mathrm{PgH}$ are protonated at this $\mathrm{pH}$, any other intermolecular forces such as hydrogen bonding between protonated carbox$\mathrm{yl}$ groups and ethereal oxygens of $\mathrm{PgHs}$ and/or a hydrophobic effect of protonated carboxyl groups might participate in the intermolecular aggregation of $\mathrm{PgH}$, which induced a suppression of the transmittance increment.

For $\mathrm{P} g \mathrm{H} / \alpha$-CD IC hydrogels formed at relatively higher concentrations (e.g., $3 \mathrm{wt} \%)$ of $\mathrm{P} g \mathrm{H}$, a gelmelting temperature $\left(T_{\text {gel-melt }}\right)$ was estimated as a function of $\mathrm{pH}$. The result is shown in Figure 8. $T_{\text {gel-melt }}$ increased with DS due to the increase of physical crosslinks, which was well consistent with the result regarding the dissociation temperatures of $\mathrm{PgH}$ / $\alpha$-CD suspensions (Figure 7). As for $\mathrm{pH}$-dependency, $T_{\text {gel-melt }}$ significantly increased with decreasing $\mathrm{pH}$ at every DS. In the case of $\mathrm{P} g \mathrm{H}-1, \mathrm{P} g \mathrm{H}-1 / \alpha-\mathrm{CD}$ IC did not show hydrogelation at $\mathrm{pH} 9$; it became turbid solution. The data in Figure 8 suggests that the hydrogelation of $\mathrm{PgH}$ with $\alpha$-CD is $\mathrm{pH}$-dependent. As has been discussed above, lower $\mathrm{pH}$ provides protonated carboxyl groups of $\mathrm{P} g \mathrm{H}$, which can participate in the formation of physical crosslinks consisting of hydrogen bonding in these hydrogels. The difference in $\mathrm{pH}$-dependency between the dissociation temperature of the $\mathrm{PgH} / \alpha$-CD IC suspension (Figure 7) and the melting one of the $\mathrm{P} g \mathrm{H} / \alpha-\mathrm{CD}$ IC hydrogels (Figure 8 ) is considered to be ascribed to the contribution of carboxyl groups in $\mathrm{P} g \mathrm{H}$ to physical crosslinks

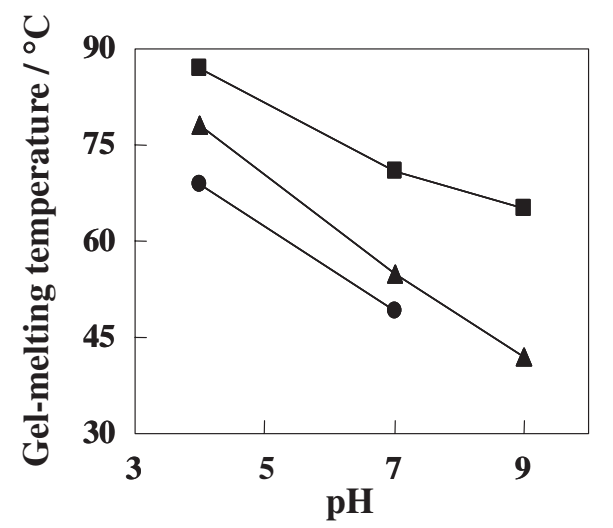

Figure 8. Gel-melting temperature of hydrogels of $\mathrm{P} g \mathrm{H} / \alpha$ CD ICs with different DSs: $\bullet, D S=0.09 ; \boldsymbol{\Delta}, \mathrm{DS}=0.18$; $\mathrm{DS}=0.28$. of IC, in the form of hydrogen bonding between protonated carboxyl groups and ethereal oxygens of $\mathrm{P} g \mathrm{Hs}$ and/or a hydrophobic effect of protonated carboxyl groups.

\section{CONCLUSION}

New HA-based hydrogels consisting of $\mathrm{P} g \mathrm{H}$ and $\alpha$ $\mathrm{CD}$ were constructed by inclusion complexation between the PEG grafts and $\alpha-\mathrm{CD}$. The DS of the PEG grafts was controlled by the feed ratio of PEG to HA. The solid-state ${ }^{13} \mathrm{C} \mathrm{CP} / \mathrm{MAS}$ NMR spectroscopic and powder X-Ray diffraction measurements revealed the inclusion complexation between the PEG grafts and $\alpha$-CD. The gel-melting temperature increased with increasing DS of the PEG grafts and decreasing $\mathrm{pH}$ of the aqueous medium. This finding suggests that not only ICs between the PEG grafts and $\alpha-\mathrm{CD}$ but also protonated carboxyl groups of $\mathrm{PgH}$ contribute to the formation of physical hydrogels. Therefore, the gel-melting temperature of $\mathrm{P} g \mathrm{H} / \alpha-\mathrm{CD}$ systems could be controlled by $\mathrm{pH}$ as well as DS of the PEG grafts. Most recently, it was found that $\mathrm{P} g \mathrm{H}$ solution with a high molecular weight HA exhibiting phase separation between HA and PEG induces hydrogelation much faster than homogeneous $\mathrm{P} g \mathrm{H}$ solution on adding $\alpha$-CD. ${ }^{15}$ Thus, HA hydrogelation using inclusion complexation between the PEG grafts and $\alpha$-CD will emerge a new field of hydrogels showing a rapidly stimuli-responsive change of the physicochemical properties.

Acknowledgment. The authors thank Prof. S. Sasaki, Japan Advanced Institute of Science and Technology (JAIST), for Powder X-Ray diffraction measurements and the financial support of a Grantin Aid for Scientific Reserch (B1) (No. 13558106), from Ministry of Education, Culture, Sports, Science, and Technology of Japan.

\section{REFERENCES}

1. T. Nishikawa, K. Akiyoshi, and J. Sunamoto, J. Am. Chem. Soc., 118, 6110 (1996).

2. S. J. de Jong, B. van Eerdenbrugh, C. F. Van Nostrum, J. J. Kettenes-van den Bosch, and W. E. Hennink, J. Control. Release, 72, 47 (2001).

3. B. S. Lele and A. S. Hoffman, J. Control. Release, 69, 237 (2000).

4. J. Li, A. Harada, and M. Kamachi, Polym. J., 26, 1019 (1994)

5. a) T. Ooya and N. Yui, Crit. Rev. Ther. Drug Carrier Syst., 16, 289 (1999).

b) T. Ooya and N. Yui, Macromol. Chem. Phys., 199, 2311 (1998).

c) T. Ooya and N. Yui, J. Control. Release, 58, 251 (1999). 
d) T. Ooya, M. Eguchi, and N. Yui, J. Am. Chem. Soc., 125, 13016 (2003).

6. a) J. Watanabe, T. Ooya, and N. Yui, Chem. Lett., 10, 1031 (1998).

b) J. Watanabe, T. Ooya, and N. Yui, J. Biomater. Sci., Polym. Ed., 10, 1275 (1999).

c) T. Ichi, J. Watanabe, T. Ooya, and N. Yui, Biomacromolecules, 2, 204 (2001).

7. K. M. Huh, T. Ooya, W. K. Lee, S. Sasaki, I. C. Kwon, S. Y. Jeong, and N. Yui, Macromolecules, 34, 8657 (2001).

8. H. S. Choi, K. Kontani, K. M. Huh, S. Sasaki, T. Ooya, and N. Yui, Macromol. Biosci., 2, 298 (2002).

9. a) K. Moriyama, T. Ooya, and N. Yui, J. Control. Release, 59, 77 (1999).

b) S. T. Lim, G. P. Martin, D. J. Berry, and M. B. Brown, J. Control. Release, 15, 281 (2000).

c) Y. Luo, M. R. Ziebell, and G. D. Prestwich, Biomacromolecules, 1, 208 (2000).

d) Y. Luo, R. Kirker, and G. D. Prestwich, J. Control. Release, 3, 169 (2000). e) M. R. Kim and T. G. Park, J. Control. Release, 23, 69 (2002).

10. a) L. S. Liu, A. Y. Thompson, M. A. Heidaran, and J. W. Poster, Biomaterials, 20, 1097 (1999).

b) S. Ohya, Y. Nakayama, and T. Matsuda, Biomacromolecules, 2, 856 (2001).

c) S. N. Park, J. C. Park, H. O. Kim, M. J. Song, and H. Suh, Biomaterials, 23, 1205 (2002).

11. a) N. Yui, T. Okano, and Y. Sakurai, J. Control. Release, 22, 105 (1992).

b) N. Yui, J. Nihira, T. Okano, and Y. Sakurai, J. Control. Release, 25, 133 (1993).

12. T. Pouyani, G. S. Harbison, and G. D. Prestwich, J. Am. Chem. Soc., 116, 7515 (1994).

13. A. Harada, J. Li, and M. Kamachi, Macromolecules, 26, 5698 (1993).

14. M. J. Gidley and S. M. Bociek, J. Am. Chem. Soc., 110, 3820 (1988).

15. T. Nakama, T. Ooya, and N. Yui, Macromol. Rapid Commun., in press (2004). 